\title{
Two-stage Hands-on Technology Activity to Develop Preservice Teachers' Competency in Applying Science and Mathematics Concepts
}

\begin{abstract}
This paper discusses the implementation of a two-stage hands-on technology learning activity, based on Dewey's learning experience theory that is designed to enhance preservice teachers' primary and secondary experiences in developing their competency to solve handson problems that apply science and mathematics concepts. The major conclusions were that: (1) Preservice teachers understood the science and mathematics concepts related to the handson activity, but they need more help in exploring practical products of applying discipline related concepts for the purpose of stimulating their design ideas; and (2) The two-stage hands-on technology learning activity served as useful prompts in developing preservice teachers' primary and secondary experiences in applying science and mathematics concepts during the design process. However, it was evident that preservice teachers still needed more training in improving their design ideas by the application of more in-depth related science and mathematics concepts.
\end{abstract}

Keywords: Mathematics, Preservice teacher, Science, Technology, Two-stage hands-on learning activity 


\section{Introduction}

A significant issue in traditional, knowledge based science and mathematics education is the lack of opportunities for applying mathematics and science to everyday meaningful problems (Johnson, 1989). One possible way to address this issue is for students to develop problemsolving skills by applying science and mathematics concepts through technology activities which are focused on hands-on learning (Blackwell \& Henkin, 1989; Daugherty \& Wicklein, 1993; Davis \& Gilbert, 2003; Martin-Kniep, Feige, \& Soodak, 1995). However, the question arises as to whether it is possible for students to satisfactorily integrate theory to solve practical problems by applying their science and mathematics concepts? This is a question to which researchers of hands-on learning are seeking answers.

Research results to date have been disappointing because most studies have found that students usually proposed their design ideas by intuition, or prior experiences, and have struggled to apply their science and mathematics concepts in hands-on learning activities (Childress, 1996; Yu \& Lin, 2007). A possible reason is that practical problems are typically unstructured and complex in our daily life (Strough, Cheng, \& Swenson, 2002; Yu, Lin, \& Hung, 2010), and therefore, when faced with these problems, students tend to resort to, and apply intuition, rather than draw upon their science or mathematics knowledge (Strough, Cheng, \& Swenson, 2002). Yu et al. (2010) used a repeated hands-on learning strategy to explore possible reasons for the gap between knowing and applying concepts in solving practical problems. The students progressed through an iterative design and make process in developing water rockets, while reflecting on the problems they encountered and solved throughout the activity.

In that study, it was reported that the key factors affecting the flight distances of the water rockets were the students' lack of technical skills in the initial stages (the first and second water rockets); lack of the design skills in the middle stages (the third and fourth water rockets), and lack of application of scientific concepts in the final stage (the fifth water rocket). These results indicated that when students encountered problems, they did not attempt initially to apply their scientific knowledge but first had to solve the technical and design problems in selecting and manipulating materials, after which they sometimes applied their science concepts. It seems that engagement in practical activities can help students apply science and mathematics concepts to their problem solving, but it is not clear how to complement the use of intuition with concepts to solve problems in order to help the students develop the technical and design skills required before applying abstract and challenging concepts. These are key issues for teaching technology.

Yu et al. (2010) found that repeated hands-on learning helped students to integrate theory and practice, however the students lacked interest in the repetitive design process. In order to overcome this lack of interest, it was decided that the main purpose of this study would be to develop the means for helping students to apply science and mathematics concepts in their problem solving by developing no-repeat and meaningful hands-on learning activities (Dewey, 1929; Dewey, 1938). According to Dewey's theory, the primary experience of learning is when students imprint emotive, psychological, physical, and sensory data onto their minds during the hands-on learning processes and experiences. Hence, through the development of the primary experience in hands-on learning, students may be able to develop their technical and design skills (Dewey, 1929). The secondary experience of learning entails applying rational processes to analyzing and classifying the primary experience, thus enhancing the learning process through reflection. Therefore, secondary experience learning 
should enhance students' design skills and problem solving through the in-depth application of science and mathematics concepts (Dewey, 1929).

In summary, this study embedded recent research results within Dewey's theory (Dewey, 1929). Based on this synthesis, we designed a two-stage hands-on learning activity to enhance the development of students' problem solving competencies through the application of science and mathematics concepts. Hence, the main aim of this study was to explore the usefulness of this two-stage hands-on learning activity for students in developing their competency in problem solving based on the deep understanding and application of science and mathematics concepts.

\section{Two-stage hands-on technology learning activity}

Hands-on learning activity used in the integration of science and mathematics concepts is sometimes seen as a "black box." Some technology teachers have introduced science and mathematics concepts before a hands-on learning activity and then test students' performance in science and mathematics after the activity (Yu \& Lin, 2007). It is apparent that these teachers do not seem concerned about how students incorporate and apply their science and mathematics concepts during the hands-on learning process (Childress, 1996; Merrill, 2001; Yu \& Lin, 2007). Hence, even when students are involved in hands-on learning activities, they may not learn how to apply science and mathematics, which results in a dependence on their intuition (Yu \& Lin, 2007). One area of research has focused on this "black box" view of the hands-on learning process (Weiss, Knapp, Hollweg, \& Burrill, 2001), see [Figure 1]. Dow (2006) highlighted the importance of actively encouraging students to apply science and mathematics concepts during hands-on activities, thus making learning more meaningful and relevant, which is one of the most important issues for teachers. Besides, Dow (2006) also proposed the argument that teacher beliefs or theories are a crucial factor in preventing change; that is, how to help teachers in overcoming the barriers to change should be explored in hands-on teaching.

\section{[Figure 1]}

Dewey's (1938) book Experience and Education is often cited as the theoretical basis for hands-on learning. Dewey focused on offering an experiential learning environment to students, including learning by doing, and understanding connections through active and reflective thinking. However, learning by doing can be misunderstood, resulting in students learning only about the experiences related to the hands-on learning activity itself. In practice, many students participate in hands-on learning activities using a trial and error approach and they lack an understanding of the methods involved and fail to make connections with previous learning experiences (Yu, Lin, \& Fan, 2013). Dewey (1944) believed that trial and error does help students in developing experiences, but students have to make connections between their actions and results through reflective thinking for improving their experiences. Therefore, according to Dewey (1938), a hands-on learning activity cannot simply focus on participating in the activity. Hence, one of the important aspects of teaching through hands-on experience is to know how to help students connect their actions and experiences through reflective thinking. Puntambekar and Kolodner (2005) implemented distributed scaffolding in helping students learn science from design, and put forth the notion of distributed scaffolding as an approach to support hands-on inquiry learning. This study was also inspired by the study, and attempts to gain an insight on 
potential chances in helping students connect actions and experiences consistent with scaffolding in Puntambekar and Kolodner's study.

How do we help students connect their actions and prior experiences through reflective thinking? Dewey (1938) believed that experience is not always necessarily educative, for example, some experiences may actually hinder their education and the development of appropriate understandings. Therefore, to be of value, the experiences accumulated through a hands-on learning activity have to meet the following criteria (Dewey, 1938): (1) the principle of continuity of experience: each experience not only links with prior experience, but may be modified in some way in the future, that is, students' experiences should be connected between different hands-on technology activities, and they also have to learn to apply these experiences in solving future problems ; (2) the principle of interaction with the experience: the interaction between students and the learning environment, that is, students can learn relevant knowledge and skills in the past, and these can become effective tools for understanding and dealing with future problems. Sternberg (2009) also proposed a model of complex problem solving, and believed that the inference, corresponding, and application are three important factors for applying knowledge in solving complex problem solving. Besides, in Puntambekar and Kolodner's (2005) study, they designed a scaffolding tool in supporting students' design-related activities, and found that students need multiple forms of support and multiple learning opportunities to learn science from design activities. That is, the design of hands-on learning activity should be focused on providing multiple learning opportunities in connecting their experiences or concepts with problems.

Dewey (1998) believed that the most effective learning is derived from problem solving, and problem solving is a process that involves reflective thinking. Thus, students can learn to apply their own knowledge during the problem-solving processes. Only through the processes of reflective thinking can students transform a primary, unreflective experience into a secondary, reflective one. Students have to construct their own understandings in order for the content taught by teachers to be transformed into learning. According to Yu et al. (2010), factors influencing students' learning performance in repeated hands-on learning activities include (a) their technical skills, (b) their design skills, and (c) their application of relevant science and mathematics concepts and understandings. If we combine Yu et al.'s (2010) research results and Dewey's (1929) theory, we can conclude that for a hands-on activity to result in effective learning, one of the possible approaches in developing students' competency in applying concepts is that students need to (a) focus on developing their technical skills as the primary experience, and (b) develop their design skills by applying science and mathematics concepts as the basis for the secondary experiences.

Although considerable research studies have concluded the importance of developing students' competency in integrating knowledge in solving practical problems, limited attention has been paid to explore preservice teachers' competency in applying concepts in solving practical problems. The aim of this study was to design a two-stage, hands-on technology learning activity to develop primary and secondary experiences among preservice teachers, in order to explore their performance in applying science and mathematics concepts in the learning activity. The two-stage hands-on learning activity involved designing and constructing firstly, a balloon car and secondly, a mousetrap car. In the balloon car activity, participants had to focus on technical skills in constructing a car from materials such as foam or cardboard, and then incorporate a balloon, as a power source, in the design, using their intuition. In the first stage of the activity, the preservice teachers were not explicitly required 
to apply any science or mathematics concepts. However, in the second stage of the activity, the researchers set up science and mathematics related design and making criteria for the participants to use as they constructed a mousetrap car. For example, to design and make a mousetrap car to travel as far as possible, the students had to use Newton's second law of motion in the design stage to find the most appropriate wheel-to-axle ratio. Alternatively, if the students were designing a mousetrap car to travel more than 10 metres, they had to take this calculation into account at the design stage and then apply the appropriate concepts from mathematics and science. As the second stage of the project was focused on students' reflective thinking, they needed to reflect on the experiences gained (or acquired) in designing and constructing the Stage 1 balloon car and then design and construct their Stage 2 mousetrap car, drawing upon their problem-solving skills and incorporating relevant science and mathematics concepts. Conceptualized as a two-stage hands-on learning activity, this study focused on exploring whether preservice teachers accumulated appropriate technical skills and experiences in the balloon car design during the Stage 1, and then tested to see whether students combined these first stage experiences with reflective thinking and applied the combination to the process of designing and constructing the mousetrap car in the Stage 2 of the activity.

\section{Methods}

\subsection{Research design}

This study was based on Dewey's (1929) theory integrated with more recent research (Yu, Lin, \& Fan, 2014; Yu, Fan, \& Lin, 2014), and the goal was to design a two-stage hands-on Technology learning activity for preservice teachers in order to provide them with opportunities to accumulate primary and secondary learning experiences and to increase their competency in problem solving involving the application of important science and mathematics concepts. According to the problem solving process in Figure 2, there are four steps in guiding preservice teachers in applying science and mathematics concepts in handson technology learning activity: (1) step A: to recall the related science and mathematics concepts applicable to balloon or mousetrap cars; (2) step B: to explore the related examples of applying science and mathematics concepts in their daily life, e.g. movement of a hovercraft can be explained using Newton's laws of motion; (3) step C: to propose design ideas in accord with relevant science and mathematics concepts; (4) step D: to construct the balloon and mousetrap cars in accord with the design ideas and criteria.

It was essential that the preservice teachers follow the four steps in designing and making balloon and mousetrap cars. In addition, three important factors were also explored during the problem solving process: (1) inference: student teachers should learn to explore and explain the related examples of science and mathematics concepts in their daily life; (2) corresponding: preservice teachers should learn to propose their design ideas that include attention to relevant science and mathematics concepts; (3) application: preservice teachers should learn to construct their product according to their design ideas. In order to develop the preservice teachers' primary and secondary understandings of these factors, the researchers required them to undertake reflective thinking during the process of problem solving. According to the research design of this study, the following three propositions were discussed in exploring the problem-solving processes (see Figure 2). 
Proposition 1: In addressing practical problems, preservice teachers should understand the related science and mathematics concepts (see step A in Figure 2). In addition, they also had to think about the related technological products that applied these science and mathematics concepts for the purpose of stimulating and enhancing their prior experiences (see step B in Figure 2). Based on these concepts and prior experiences, they could utilize these concepts and experiences in the two-stage hands-on learning activity (Figure 2A-B; Inference).

Proposition 2: After their prior knowledge and experience were engaged, preservice teachers should propose new design ideas (see step $\mathrm{C}$ in Figure 2) based on this background knowledge (Figure 2A-C: Corresponding).

Proposition 3: based on their previous design ideas, preservice teachers should produce a finished product (see step D, Figure 2C-D: Application). Through a discussion of these three propositions, this study explores how preservice teachers in the fields of science and technology can apply science and mathematics concepts to practical problem-solving scenarios in a two-stage hands-on learning activity (Figure 2).

[Figure 2]

\subsection{Two-stage hands-on technology learning activity}

In Taiwan, science and technology is combined as an independent learning field, that is, science teachers may have opportunities to teach technology education, which is focused on hands-on learning. However, they usually do not have enough experience to teach the class in a practical way. Therefore, this study attempted to develop a two-stage hands-on technology learning activity for improving their technical and design skills, and problem solving competency. One of the most important issues is to inform preservice teachers about how to teach junior-high students in applying their science and mathematics concepts in hands-on learning activities. Bybee and Loucks-Horsley (2000) believed that "if technology teachers do not understand deeply the technology concepts they are trying to teach, one cannot expect their students to learn (p.31)." That is, if we hope that preservice teachers know how to teach their students in applying science and mathematics concepts in hands-on learning activities, then the first step is to develop preservice teachers' abilities in doing this task. Therefore, 113 preservice teachers in two "Introduction to Technology Education" classes (16 majors in physics, 22 majors in chemistry, 25 majors in biology, 17 majors in earth science, 8 majors in science education and 25 majors in technology) participated in this study. All of these participants will, eventually, be science and technology teachers in secondary schools and it is hoped that they will play important roles in promoting interdisciplinary integration of science, technology, engineering, and mathematics when they have opportunities to implement such programs.

The two-stage hands-on technology activity, the focus of this study, represented the first occasion where most of the preservice teachers were exposed to this type of STEM-based instructional approach. Before the two-stage hands-on technology activity, the preservice teachers were not familiar with hands-on activities which included an emphasis on applying science and mathematics concepts in their design ideas and use of technological tools. The two-stage hands-on technology activity was taught in two sub-units during the 7 week course duration (21 hours in total; see Table 1). In the balloon car activity, the preservice teachers did not have to learn the science and mathematics concepts related to the balloon car, however, they were instructed to intuitively design a balloon car. The most important part in this activity, according to Dewey's theory (1929), was the inclusion of an attempt to focus the 
preservice teachers on the use of their technical skills in constructing a car out of foam or cardboard. For the mousetrap car activity, the aim was to instruct the preservice teachers about the relevant science and mathematics concepts, so they could apply those concepts to their design. That is, the preservice teachers had to apply related science and mathematics concepts to their mousetrap car design, and they were also requested to provide some examples of where these concepts were utilized in their respective daily lives (see the inference step in Figure 2A). Then the preservice teachers had to propose their design ideas, based on the previous examples, for improving the relationships of design ideas and concepts (see corresponding step in Figure 2). For the last step, the preservice teachers had to construct their mousetrap cars according to their most recent design ideas (see Figure 2C-D: Application).

This study focused on exploring whether preservice teachers accumulated the required technical skills and experiences during the design and construction of the balloon car in the first stage of the two-stage hands-on learning activity. We then investigated whether they combined this experience with reflective thinking, and then applied this combination in the process of designing and constructing the car in the second stage of the hands-on learning activity.

[Table 1]

\subsection{Data Collection}

During the study multiple sources of data were collected throughout the two-stage hands-on technology activity. The preservice teachers had to collect the following data: their generated ideas; important issues in raised and examined in the team discussion; record and analyse the respective performances of both the balloon car and mousetrap car; and write their personal reflections in their own learning portfolio. For example, the preservice teachers recorded their design and making processes used during both the activities, focusing on the type of knowledge they used in the design process, and the types of problems they encountered during the reflective thinking processes. In addition, and in order to further explore preservice teachers' learning performances and difficulties, in-depth interviews were conducted by the researcher. The interviews focused on collecting data that would enable the researchers to identify and analyse the difficulties encountered by the students in the two activities, and explored each preservice teacher's thoughts about their primary and secondary experiences during the activity.

\subsection{Data analysis}

To explore the research propositions, the analytic steps suggested by Erickson (1986) and Patton (1990) were followed. We first reviewed the learning portfolios and in-depth interview transcripts, and secondly identified smaller units (such as the sentences related to one concept) of coherent interaction, and then imported the data for coding. The codes used to analyze the transcripts were derived from the research propositions. We identified, from Sternberg's (2009) complex problem solving model, three important factors in applying science and mathematics concepts in the two-stage hands-on learning activity, i.e., inference, corresponding, and application. We used the set of analytic tools suggested by Strauss and Corbin (1998) to facilitate the coding process and developed a coding scheme that included factors of inference, correspondence, and application. Once these transcripts were coded, we extracted the smaller units that were identified by one or more codes and generated progress 
reports of each group. Coding of the qualitative data was based on four types of collected data:

(1) the items and their code names (listed in Table 2);

(2) the dates for all data, listed after the code names (e.g., November 27, 2012, is listed as 20121127);

(3) the case number given to the preservice teachers for identification purposes (this was the same as their student identification number, e.g., 89171001);

(4) the serial number given to each sentence of recorded data (e.g., "II20121127-8917100101 " represents the first sentence of the in-depth interview with preservice teacher 89171001 on November 27, 2012).

[Table 2]

We then reviewed the progress reports and identified coding categories for the second level of coding. These coding categories included examples related to science and mathematics concepts; examples used to propose design ideas as wells as technological products. The authors conducted a second analysis of the reports, abstracted further information around these coding categories, and produced descriptions and analytical notes in order to generate coherent themes. The themes were recurrent activities that emerged from the descriptions and notes. We searched for confirming and disconfirming evidence from different sources of data in order to to triangulate our interpretations and to increase credibility (Erickson, 1986).

\section{Findings}

In this section, we describe how the preservice teachers used science and mathematics concepts when they engaged in the two-stage hands-on learning activity based on the analysis of data in the learning portfolios and in-depth interviews. Each subsection begins with a general description of a finding, which is then elaborated upon by using examples drawn from the data. These examples provide evidence of preservice teachers' hands-on practices in applying science and mathematics concepts and illustrate the findings in detail.

\subsection{Preservice teachers' performances in exploring the practical products of applying related science and mathematics concepts during the construction of balloon and mousetrap cars, in their daily lives}

Weiss et al. (2001) asserted that some technology teachers viewed students' knowledge application as a 'black box' in hands-on learning activity. In order to help students in applying science and mathematics concepts in hands-on learning activity, this study design incorporated a two-stage hands-on learning activity for students to understand how to apply science and mathematics concepts in their design ideas. For the first stage of the activity, the researcher just allowed preservice teachers to propose their design ideas by intuition, without the assistance or guidance of the teacher.

The data from the learning portfolios for the balloon car provided evidence that most preservice teachers understood the basic scientific principles underpinning the construction 
and operation of the balloon cars, such as friction, Newton's laws, and calculations of circumference and wheel-to-axis ratios. Therefore, they tended to focus on analyzing the problem in front of them and did not think about how their knowledge could be applied to related issues that might be encountered in practical problems in their daily life. For example, according to the results in the balloon car construction, data showed that the preservice teachers possessed the relevant knowledge, but they did not apply it to problem solving (Sample data sources: II20121030-40171102H-11; II20130416-497730511-03). This was highlighted in the difficulties (II20130416-497730511-03) they encountered in applying their science and mathematics concepts in designing the balloon car. The findings are similar to those of Baumann and Kuhl (2002), who reported that, when faced with novel situations and unstructured problems, people solved them using their intuition instead of applying a strategic analysis of any problem areas. Chi et al. (1988) believed that during the problemsolving process, experts spend more time analyzing and understanding the problem, whereas novices tended to look for quick solutions. This assertion is confirmed in our study. For example, the preservice teachers lacked the ability to apply their pre-existing science and mathematics concepts, which is evident in an extract from the qualitative data shown below.

"We put forward our ideas according to the related data, or just using our intuition..." (II20121030- 40171102H-11)

"I think that it is hard for me to think about how (to)use science or mathematics concepts and apply it to solve everyday problems. Even if I can suggest an example, I may still not understand how to apply it." (II20130416-497730511-03)

However, in the second stage activity, the researcher utilized Dow's approach (Dow, 2006) to encourage preservice teachers to think about what types of products in their daily lives, may be applications of the science and mathematics concepts embodied in the design and construction of the mousetrap car. For example, when the lever principle was mentioned, Team 101-1-7 thought immediately about the design of a trebuchet (LP2013040160241040S-01, see Figure 3) and they argued that the structure of trebuchet would be helpful to them in designing their mousetrap car. Based on the records of preservice teachers' learning portfolios in the mousetrap car activity, 21 of 24 teams proposed similar products in their daily lives, and 18 teams believed that these products were helpful in assisting them to propose their own design ideas for the mousetrap car. Therefore, with regard to research proposition 1 ("Preservice teachers should understand the related science and mathematics concepts for practical problems, and know how to apply them to stimulate their prior knowledge and experiences by exploring related examples in a two-stage hands-on learning activity"; Fig. 2A-B), it is believed that preservice teachers know the related science and mathematics concepts embodied in the construction and use of the balloon and mousetrap cars. However, if they are not guided in exploring related examples in their daily lives, they tend to seek solutions by intuition instead of investigating similar examples. Therefore, we suggest that in teaching future hands-on learning activities, ultimately these preservice teachers should guide their own future students to think about examples and benefits of when they did apply their own pre-existing science and mathematics concepts to solve other problems.

[Figure 3] 


\subsection{Preservice teachers' performances in applying science and mathematics concepts to their design ideas in the two-stage hands-on learning activity}

The key issue was how the preservice teachers applied their pre-existing knowledge through the design processes to improve the operational performance of the two types of cars they constructed made. If the teachers applied their knowledge in the design process, then that would suggest that the hands-on learning was helpful in integrating theory with practice. This question is related to the second research proposition, "After stimulation of prior knowledge and experience, preservice teachers should propose a complete set of design ideas based on this knowledge" (Fig. 2A-C). To help preservice teachers in applying science and mathematics concepts in suggesting design ideas, we proposed a two-stage hands-on learning activity. In the first stage, the preservice teachers had to design and make a balloon car, thus learning the essential technical skills as well as experiencing the importance of applying their background science and mathematics content knowledge and associated conceptual understanding. Analysis of our research results evident in the preservice teachers' learning portfolios, and collected during in-depth interviews, showed that the preservice teachers did not think to apply their pre-existing science and mathematics concepts, as they lacked experience in applying this knowledge in a hands-on learning activity. For example, the preservice teachers in Team 101-1-7, just presented draft thoughts in their design ideas and did not think about how to apply the science and mathematics concepts in their design conceptualisations (see Figure 4).

[Figure 4]

After the first stage of the hands-on learning activity, the researchers guided the preservice teachers to reflect on and review the processes involved in the second activity. They were asked to think about the importance of applying science and mathematics concepts in a hands-on learning activity and encouraged to propose design ideas using these concepts. Analysis of the preservice teachers' applications of their knowledge showed that most teams attempted to apply both their mathematics and science concepts in the hands-on learning activity (LP20120925-498431136-01, LP20130226 -896410055-01).

"The science and mathematics concepts are very important to us, and we used these concepts in designing our mousetrap car. Before we made the mousetrap car, these concepts were a major factor in helping our design. " (LP20120925-498431136-01)

"We applied more science and mathematics concepts in the mousetrap car, and I also find it important to consider related science and mathematics concepts in advance before making the mousetrap car." (LP20130226-498432271-01)

As we can see in Figure 5, the preservice teachers already tried to apply science (friction, inertia et al.) and mathematics (wheel-to-axis ratio, circumference et al.) concepts in their design ideas, but there were still three teams who did not apply any science and mathematics concepts in their design ideas. Despite their attempts to apply their pre-existing science and mathematics concepts, this study found that there remained misconceptions of some relevant science concepts evident when they applied their knowledge of science and mathematics concepts. The possible reason could be the lack of hands-on learning experiences for these three teams; that is, the preservice teachers' respective majors (clarify this term) were not in technology. Hence, they still tended to use their intuition. Therefore, it may still be hard for 
them to know how to apply science and mathematics concepts in proposing design ideas, even though they had already participated in the two-stage hands-on technology activity.

\section{[Figure 5]}

For example, when the preservice teachers were asked to design a mousetrap car, they had to propose ideas to make a car that would travel further than 10 metres. In order to ensure that their model vehicle would travel the required distance they had to calculate the length of the driveshaft and the wheel-to-axis ratio to estimate the travelling distance. The possible travel distance of the mousetrap car was $2 *$ (the length of drive shaft)*(ratio of wheel to axis), but some teachers misunderstood that they had to calculate the wheel circumference, making their answer, $\pi *$ (the length of driven shaft)*(ratio of wheel to axis) (see Figure 6 ). One problem may have been that the preservice teachers did account for the fact that the rope would be fastened when the mousetrap car is moving forward, and therefore, the maximum achieved distance would depend on the diameter rather than the circumference of the wheel.

[Figure 6]

Previous analysis has demonstrated that two-stage hands-on learning technology activities are helpful for guiding preservice teachers how to incorporate and apply science and mathematics concepts when proposing design ideas in this study. However, the experience of the two-stage hands-on learning technology activity may be not enough to equip them with a full competence in proposing design ideas using their science and mathematics concepts. On the one hand, preservice teachers may have some misconceptions in utilizing science and mathematics concepts. On the other hand, they also have to continue maintaining their continuity of experiences for the purpose of exploring how to utilize these experiences in solving different problems and questions (Dewey, 1938). In other words, the experiences acquired during the implementation of the two-stage hands-on learning activity are not enough and the preservice teachers have to accumulate more experiences by participating in more hands-on learning activities. Therefore, future studies should focus on how to overcome the limitations identified in this paper, including preservice teachers' possible misconceptions about the application of their pre-existing knowledge (reference?) and how to let preservice teachers accumulate their continuity of experience in applying science and mathematics concepts in hands-on technology activity.

\subsection{Preservice teachers' performances in building a product based on their previous design ideas in the two-stage hands-on learning activity}

In a hands-on learning activity, it is vital that the performances of the end products meet the pre-determined design and performance criteria. The preservice teachers' products, made according to their designs, must be functional. Therefore, with respect to research proposition 3 (i.e., "Based on their previous design ideas, preservice teachers should arrive at a finished product"; Fig. 2C-D), the question is whether teachers made the product according to their design ideas in the two stage hands-on learning activity? In the balloon car hands-on activity, the teachers used their intuition to come up with a design and, therefore, the final products were often different from their initial design ideas. However, in the mousetrap car hands-on activity, the teachers used related science and mathematics concepts in their designs and, therefore, the final products were very similar to their original design ideas. The data (Table 3 ) from the balloon car activity indicate that six teams did not meet the basic criterion, as 
their cars did not travel more than 5 metres. Five of the six teams whose cars did not meet the basic criterion, did not apply any mathematics or science in their design processes.

In the mousetrap car activity, only three teams failed to build cars that could travel more than 10 metres. Despite considering application of science and mathematics in their designs, the three teams that failed to meet the prescribed criteria did not engage with relevant ideas and designs in their learning portfolio. However, there were six teams in the balloon car activity, who were able to construct a mousetrap car that travelled in excess of the target distance of 10 metres. The major reason (based on the collected data) is that they already knew the importance of applying science and mathematics concepts in proposing their design ideas. The six teams whose balloon cars did not meet the basic criterion, did apply science (friction, Newton's laws of motion et al.) and mathematics (wheel-to-axis ratio, circumference et al.) concepts in their design ideas of mousetrap cars. Besides, they also can build their mousetrap car based on their design ideas. These results indicate that the performances of the preservice teachers' end products are related to their design ideas, and the quality of their designs is related to their ability to use science and mathematics concepts to underpin the design and construction of the artefact.

[Table 3]

In summary, the preservice teachers did not use their mathematics and science concepts in designing the first-stage hands-on activity. This led to frequent on-going product revisions depending on their test results. In the second hands-on activity, most preservice teachers did use their initial designs to make the products. As they had applied science and mathematics concepts in proposing and preparing their design ideas, they only needed to make minor revisions to their end products. For the two-stage hands-on activities, the key factor is the quality of the design ideas, which should be informed by a deep understanding of relevant science and mathematics concepts, rather than by students' intuition and trial and error attempts.

\section{Conclusions}

This study aimed to integrate the authors' previous research with Dewey's theory (1929) of knowledge and action. Underpinning the study, it was the authors' intention to design and use a two-stage technology learning activity to develop students' primary and secondary experiences in solving problems by applying science and mathematics concepts. To explore preservice teachers' performance in applying science and mathematics concepts to two activities (a balloon car; a mousetrap car), three research propositions were examined. We reached the following conclusions:

Firstly, preservice teachers understood the related science and mathematics concepts in the hands-on learning activities, but they still required more guidance in stimulating their prior knowledge and experiences by exploring the practical products of applying related science and mathematics concepts in a two-stage hands-on learning activity. In Puntambekar and Kolodner's (2005) study, they also found that students need multiple forms of support to learn science from design activities. That is, the technology teachers should offer more practical examples in explaining concepts related to the hands-on learning activity, and students will have chance to recall the science or mathematics concepts or reflect their life experiences. 
Secondly, the two-stage hands-on learning activity was helpful to preservice teachers in making them think about how to apply science and mathematics concepts during the design process. However, the experiences were in sufficient to enable them to improve their designs because we found that there remained misconceptions of some relevant science concepts evident when they applied their knowledge of science and mathematics concepts. Although we tried to use inference, corresponding, and application as scaffolding tools, which is inspired by Puntambekar and Kolodner's (2005) study, in developing students' competency in applying concepts during the design process. We still found that preservice teachers still need more supports or hands-on experiences in exploring how to apply science and mathematics concepts in improving design ideas during the design process.

Thirdly, the teams that failed to meet the evaluation criteria in the hands-on learning activity had difficulty in applying science and mathematics concepts in revising their design ideas. Due to the bad quality of their designs, their mousetrap cars had more chance to fail in meeting the evaluation criteria (10 metres). In Yu et al.'s (2010) study, the technical skills are the key factor in the initial stage, but the application of science concepts is the key factor in the final stage. That is, if the preservice teachers have chance to develop their technical skills in stage 1 (balloon car), and their competency of applying science and mathematics concepts will affect their performance in building a product (mousetrap car). In addition to the previous explanation, the other possible reason is that if the preservice teachers do not develop their technical skills in the stage 1, and they will also have not enough technical skills to build a product in stage 2 . Therefore, technical skills are also the possible reason in explaining the teams that failed to meet the evaluation criteria in the hands-on learning activity.

Based on the outcomes of this study, it is believed that if the preservice teachers have relevant experiences in applying their science and mathematics concepts in the two-stage hands-on technology learning activity, they will have a better chance to help junior-high students in integrating theory with practical problems instead of just learning the theories of science and mathematics education (Johnson, 1989). That is, our students will have an opportunity to learn how to apply their science and mathematics conceptual understandings in their daily life instead of just memorizing these concepts for a test. As for the implications for further study, this study employed an action research method in exploring the possible influences in preservice teachers, but a serious quasi-experimental design should be conducted for the purpose of verifying the real effects of the two-stage hands-on technology activity in developing students' competency. Beside, students' cognitive structure of utilizing their science, technology, engineering and mathematics knowledge in solving technological problems should also be explored for improving our teaching in hands-on learning activities.

\section{Acknowledgements}

This research was funded by the Ministry of Science and Technology of the Republic of China under Contract numbers NSC 101-2628-S-003-001 and MOST 103-2628-S-003-001. The findings and recommendations contained in this article of those of the authors and do not necessarily reflect those of the Ministry of Science and Technology. We are extremely grateful to the reviewers for their helpful comments, and the preservice teachers who participated in this study.

\section{References}


Baumann, N., \& Kuhl, J. (2002). Intuition, affect, and personality: Unconscious coherence judgments and self-regulation of negative affect. Journal of Personality and Social Psychology, 83(5), 1213-1223.

Blackwell, D., \& Henkin, L. (1989). Mathematics: Report of the project 2061 phase I mathematics panel. Washington, DC: American Association for the Advancement of Science.

Bybee, R. W., \& Loucks-Horsley, S. (2000). Advancing technology education: The role of professional development. The Technology Teacher, 60(2), 31-34

Chi, M. T. H., Glaser R., \& Farr, M. J. (1988). The nature of expertise. Hillsdale, NJ: Lawrence Erlbaum.

Childress, V. W. (1996). Does integrating technology, science, and mathematics improvetechnological problem solving? A quasi-experiment. Journal of Technology Education, 8(1), 1996, pp. 16-26.

Daugherty, M., \& Wicklein, R. (1993). Mathematics, science, and technology teacher's perceptions of technology education. Journal of Technology Education, 4(2), 1993, 2843.

Davis, T., \& Gilbert, J. (2003). Modelling: promoting creativity while forging links between science education and design and technology education, Canadian journal of Science Mathematics and Technology Education, 3(1), 67-82.

Dewey, J. (1929). The quest for certainty: A study of the relation of knowledge and action. New York: Minton, Balch \& Company.

Dewey, J. (1938). Experience and education. New York: Collier Macmillan.

Dewey, J. (1944). Democracy and education. New York: The Free Press.

Dewey, J. (1998). How we think. Boston, MA: Houghton Mifflin Company.

Dow, W. (2006). The need to change pedagogies in science and technology subjects: A European perspective. International Journal of Technology and Design Education, 16(3), 307-321.

Erickson F. (1986). Qualitative methods in research on teaching. In M. C. Wittroc (Ed.), Handbook of research on teaching. New York: Macmillan Press.

Johnson, J. R. (1989). Technology: Report of the Project 2061 Phase I technology panel. Washington, DC: American Association for the Advancement of Science.

Martin-Kniep, G., Feige, D., \& Soodak, L. (1995). Curriculum integration: An expanded view of an abused idea. Journal of Curriculum and Supervision, 10(3), 227-249.

Merrill, C. (2001). Integrated technology, mathematics, and science education: A quasiexperiment. Journal of Industrial Teacher Education, 38(3), 45-61.

Patton, M. Q. (1990). Qualitative Evaluation and Research Methods, CA: SAGE.

Puntambekar, S., \& Kolodner, J. L. (2005). Toward implementing distributed scaffolding: Helping students learning science from design. Journal of Research in Science Teaching, 42(2), 185-217.

Sternberg, R. J. (2009). Cognitive psychology (5th ed.). Belmont, CA: Wadsworth/ CengageLearning.

Strauss A., \& Corbin, J. M. (1998). Basics of qualitative research: Techniques and procedures for developing grounded theory. Thousand Oaks, CA: Sage.

Strough, J., Cheng, S., \& Swenson, L. M. (2002). Preferences for collaborative and individual everyday problem solving in later adulthood. International Journal of Behavioral Development, 26(1), 26-35.

Weiss, I. R., Knapp, M. S., Hollweg, K. S., \& Burrill, G. (2001). Investigating the influence of standards: A framework for research in mathematics, science, and technology education. Washington, DC: National Academy Press. 
Yu, K. C., \& Lin, K. Y. (2007). The effect of mathematics, science, and technology integrated curriculum on students' learning achievement with different learning styles. Journal of Education Studies, 41(1), 1-16.

Yu, K. C., Fan, S. C., \& Lin, K. Y. (2014). Enhancing students' problem-solving skills through context-based learning. International Journal of Science and Mathematics Education. Advance online publication. doi: 10.1007/s10763-014-9567-4

Yu, K. C., Lin, K. Y., \& Fan, S. C. (2013). How high school students apply their knowledge in engineering design projects, International Journal of Engineering Education, 29(6), $1-11$.

Yu, K. C., Lin, K. Y., \& Hung, K. F. (2010). Teaching science through technology: A confluence of knowledge, design and making, World Transactions on Engineering and Technology Education, 8(4), 436-441.

Yu, K. C., Lin, K. Y., Fan, S. C. (2014). An Exploratory Study on the Application of Conceptual Knowledge and Critical Thinking to Technological Issues. International Journal of Technology and Design Education. Advance online publication. doi:10.1007/s10798-014-9289-5 


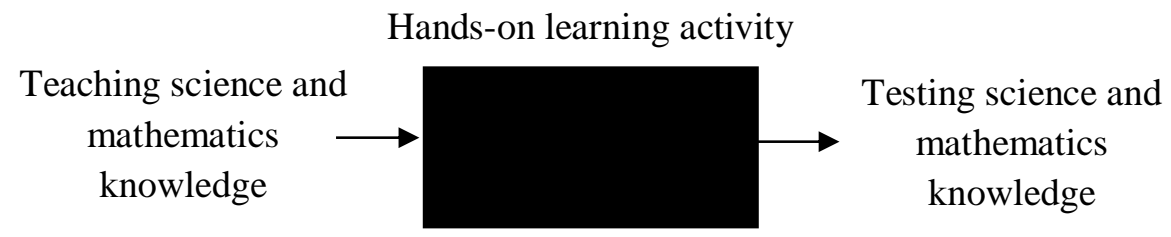

Figure 1. The black box view of hands-on learning

Source: Weiss, Knapp, Hollweg, \& Burrill, 2001, p.12. 


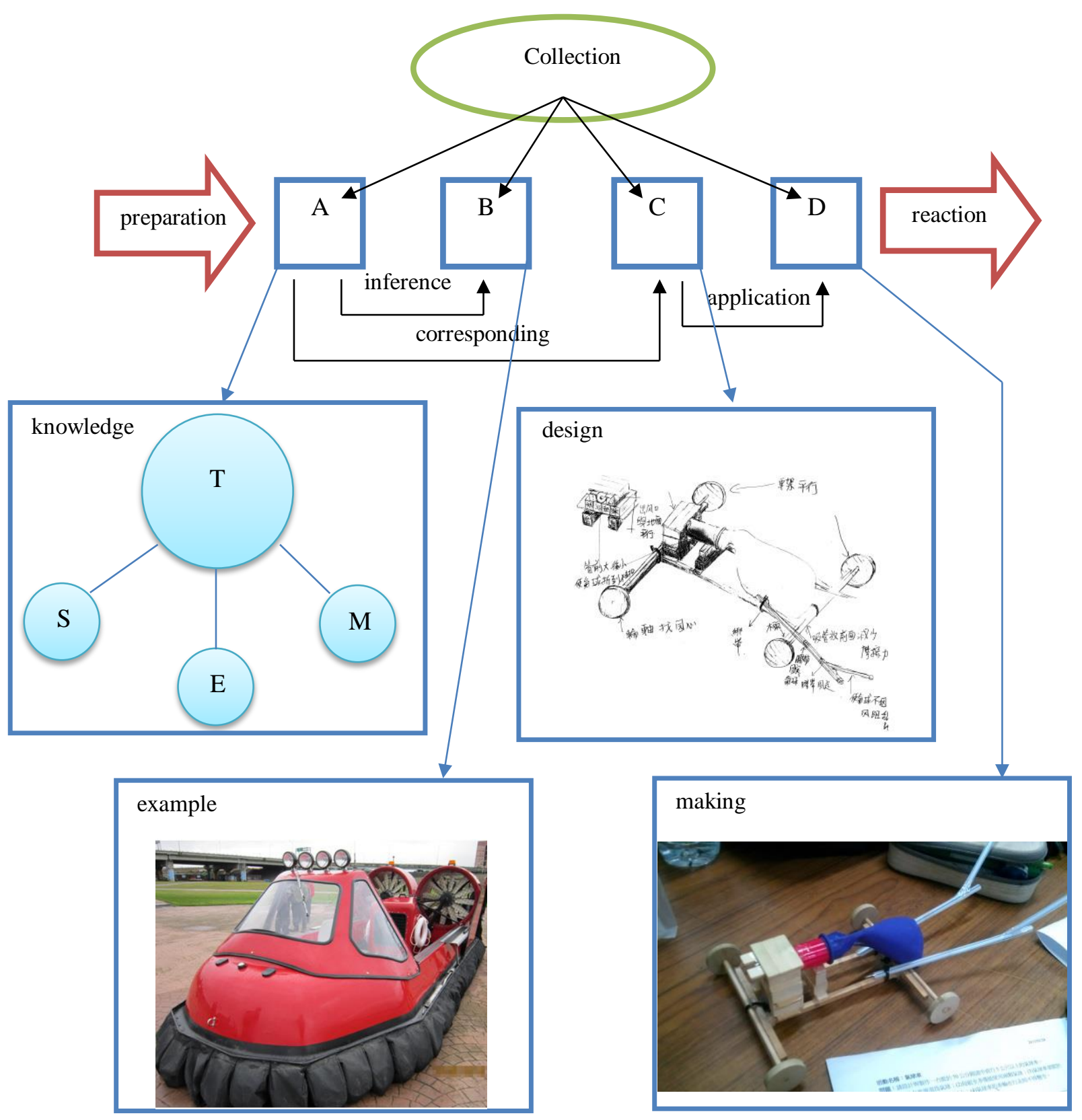

Figure 2. The research propositions of this study 


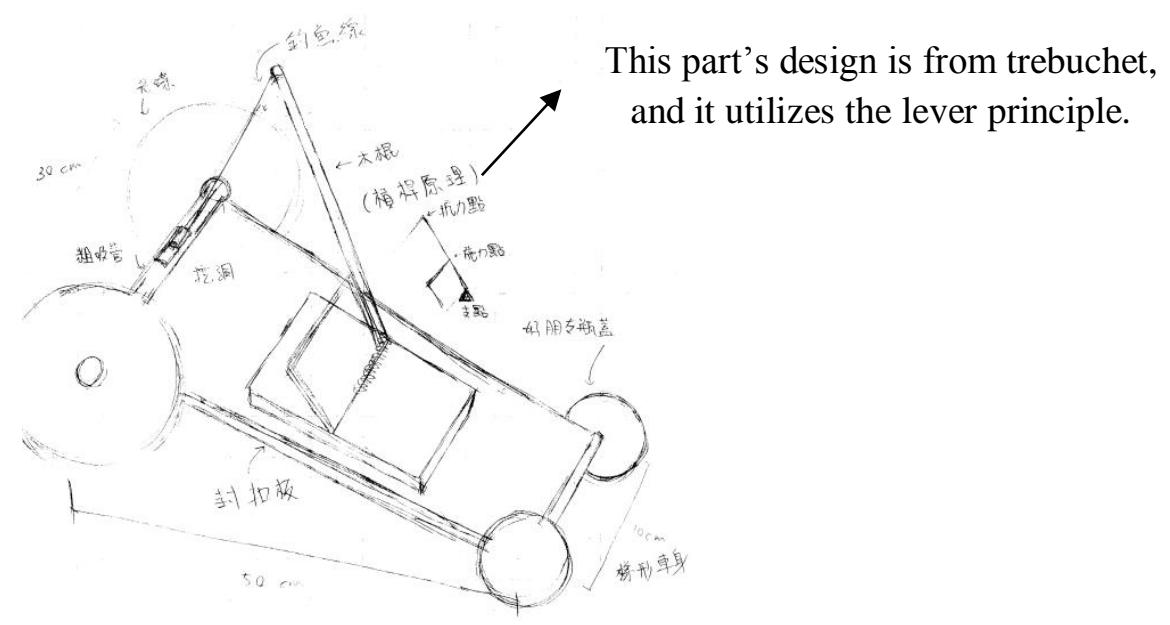

Figure 3. Student teachers' design ideas

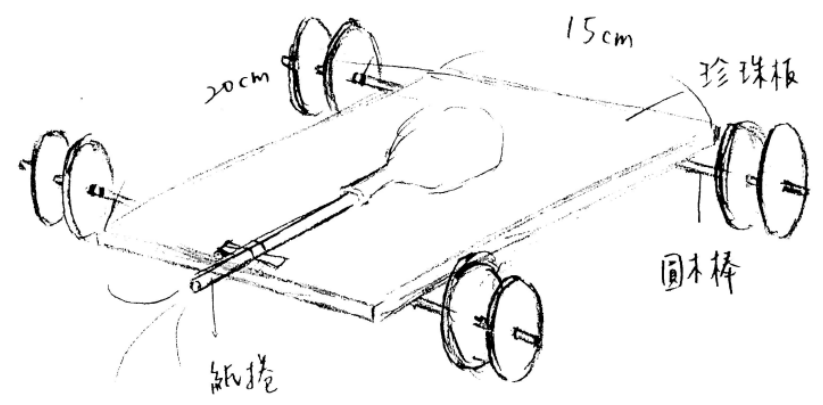

Figure 4. Student teachers' design idea in balloon car 


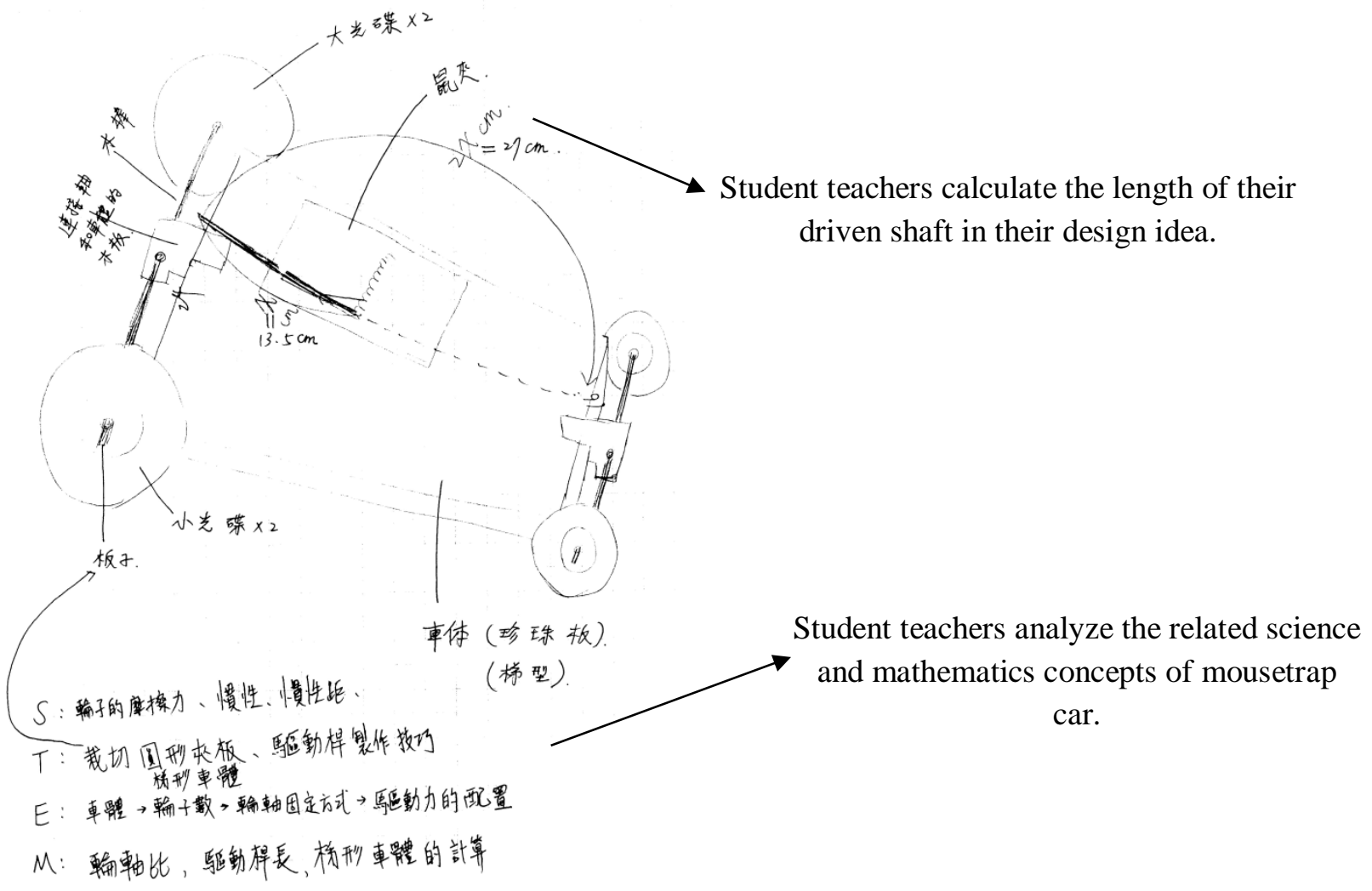

Figure 5. Student teachers' design idea in mousetrap car

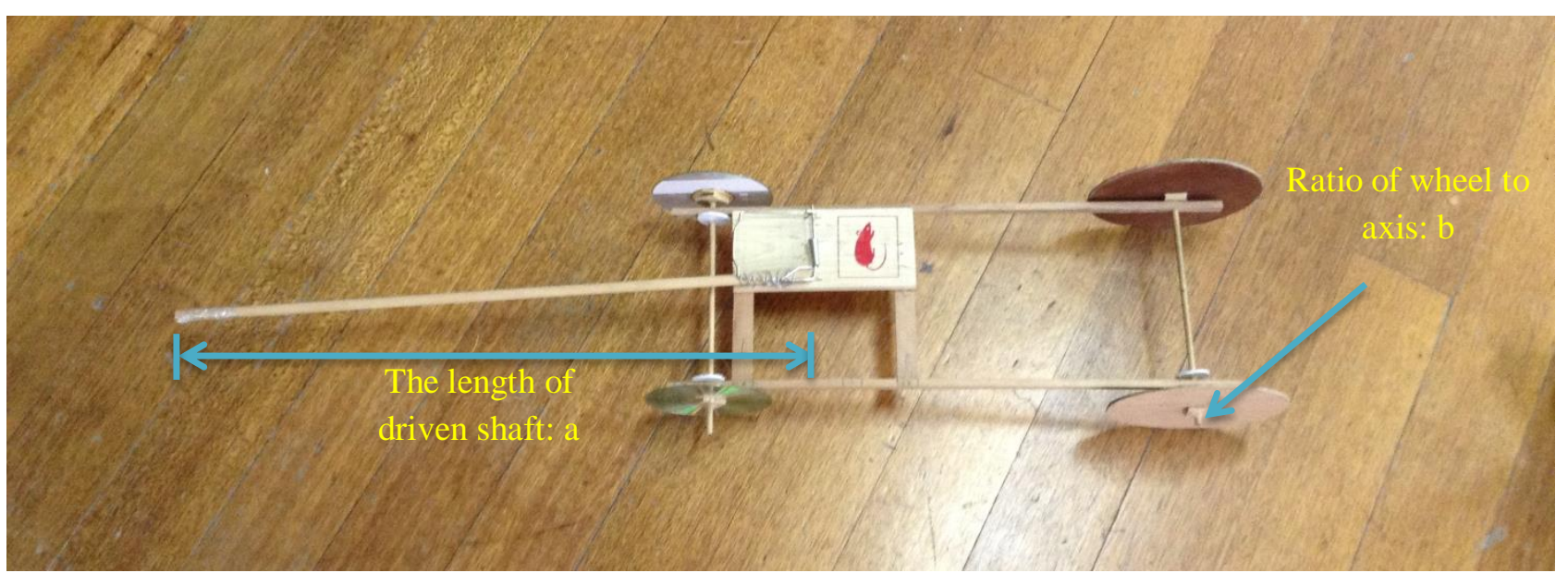

Figure 6. The calculation of estimated distance of mousetrap car 
Table 1

Overview of the two-stage hands-on technology activity

\begin{tabular}{|c|c|c|c|}
\hline & Contents & $\begin{array}{c}\text { Research propositions } \\
\text { (the process of problem solving) }\end{array}$ & $\begin{array}{c}\text { Research } \\
\text { tools }\end{array}$ \\
\hline \multicolumn{4}{|c|}{ Balloon Car } \\
\hline Week 1 & $\begin{array}{l}\text { Introduction to science and } \\
\text { mathematics concepts, } \\
\text { design (the application of } \\
\text { science and mathematics } \\
\text { concepts) }\end{array}$ & $\begin{array}{l}1 \text { and } 2 \text { (Inference, } \\
\text { corresponding) }\end{array}$ & $\begin{array}{l}\text { learning } \\
\text { portfolio }\end{array}$ \\
\hline Week 2 & $\begin{array}{l}\text { Making (according to } \\
\text { design idea) }\end{array}$ & 3 (application) & $\begin{array}{l}\text { learning } \\
\text { portfolio }\end{array}$ \\
\hline Week 3 & $\begin{array}{l}\text { Test, Modification, and } \\
\text { Reflection }\end{array}$ & & $\begin{array}{l}\text { In-depth } \\
\text { interview }\end{array}$ \\
\hline \multicolumn{4}{|c|}{ Mousetrap Car } \\
\hline Week 4 & $\begin{array}{l}\text { Introduction to science and } \\
\text { mathematics concepts, } \\
\text { design (the application of } \\
\text { science and mathematics } \\
\text { concepts) }\end{array}$ & $\begin{array}{l}1 \text { and } 2 \text { (Inference, } \\
\text { corresponding) }\end{array}$ & $\begin{array}{l}\text { learning } \\
\text { portfolio }\end{array}$ \\
\hline Week 5 & $\begin{array}{l}\text { Making (according to } \\
\text { design idea) }\end{array}$ & 3 (application) & $\begin{array}{l}\text { learning } \\
\text { portfolio }\end{array}$ \\
\hline Week 6 & $\begin{array}{l}\text { Making (according to } \\
\text { design idea) }\end{array}$ & 3 (application) & $\begin{array}{l}\text { learning } \\
\text { portfolio }\end{array}$ \\
\hline Week 7 & $\begin{array}{l}\text { Test, Modification, and } \\
\text { Reflection }\end{array}$ & & $\begin{array}{l}\text { In-depth } \\
\text { interview }\end{array}$ \\
\hline
\end{tabular}


Table 2

Items and code names

\begin{tabular}{lcc}
\hline \multicolumn{1}{c}{ Items } & Source & Code names \\
\hline 1.Documents & Learning portfolio & LP \\
2. Verbatim & In-depth interview & II \\
\hline
\end{tabular}


Table 3

Pre-service teachers' product performances in the two-stage hands-on learning activity

\begin{tabular}{|c|c|c|c|c|c|c|c|c|}
\hline \multirow{2}{*}{$\begin{array}{l}\text { Team } \\
\text { number }\end{array}$} & \multicolumn{4}{|c|}{ Balloon car (metres) } & \multicolumn{4}{|c|}{ Mousetrap car (metres) } \\
\hline & 1 & 2 & 3 & best & 1 & 2 & 3 & best \\
\hline $101-2-1$ & 2.7 & 4.2 & 3.0 & 4.2 & 6.5 & 5.0 & 10.4 & 10.4 \\
\hline $101-2-2$ & 4.4 & 7.3 & N/A & 7.3 & 5.2 & 5.4 & 11.2 & 11.2 \\
\hline $101-2-3$ & 1.3 & 2.2 & 8.0 & 8.0 & 15.5 & 13.5 & 12.7 & 15.5 \\
\hline $101-2-4$ & 4.4 & 4.6 & 5.8 & 5.8 & N/A & 17.2 & N/A & 17.2 \\
\hline $101-2-5$ & N/A & 3.4 & 5.6 & 5.6 & 15.3 & 6.3 & 13.1 & 15.3 \\
\hline $101-2-6$ & 6.6 & 5.2 & 8.3 & 8.3 & 12.6 & 13.8 & 19.8 & 19.8 \\
\hline $101-2-7$ & 1.2 & 4.2 & 4.3 & 4.3 & 13.0 & 10.1 & 11.6 & 13.0 \\
\hline $101-2-8$ & 7.6 & 7.0 & 5.0 & 7.6 & 11.8 & 16.2 & 14.3 & 16.2 \\
\hline $101-2-9$ & 4.8 & 5.0 & 9.3 & 9.3 & 5.2 & 4.4 & 16.4 & 16.4 \\
\hline $101-1-1$ & 6.2 & N/A & 12.6 & 12.6 & 9.2 & 10.7 & 13.1 & 13.1 \\
\hline $101-1-2$ & N/A & N/A & 5.0 & 5.0 & 17.0 & 16.8 & 17.4 & 17.4 \\
\hline 101-1-3 & N/A & N/A & N/A & 0 & 9.4 & 13.5 & 15.3 & 15.3 \\
\hline $101-1-4$ & N/A & 9.1 & N/A & 9.1 & 9.9 & 10.4 & 11.2 & 11.2 \\
\hline $101-1-5$ & N/A & 5.6 & N/A & 5.6 & 13.1 & 13.1 & 13.0 & 13.1 \\
\hline $101-1-6$ & 16.8 & N/A & N/A & 16.8 & 5.9 & 3.0 & 11.9 & 11.9 \\
\hline $101-1-7$ & N/A & N/A & N/A & 0 & 14.9 & 16.8 & 15.8 & 16.8 \\
\hline $101-1-8$ & N/A & N/A & N/A & 0 & 11.6 & 10.0 & 13.9 & 13.9 \\
\hline $101-1-9$ & N/A & 6.5 & 12.3 & 12.3 & 6.5 & 6.6 & 2.0 & 6.6 \\
\hline $101-1-10$ & 5.9 & N/A & 6.2 & 6.2 & 11.9 & 12.3 & 11.5 & 12.3 \\
\hline $101-1-11$ & 10.8 & N/A & N/A & 10.8 & 6.4 & 5.4 & 10.4 & 10.4 \\
\hline $101-1-12$ & N/A & 9.2 & N/A & 9.2 & 11.1 & 12.6 & 11.0 & 12.6 \\
\hline $101-1-13$ & N/A & 6.1 & 9.1 & 9.1 & 3.6 & 4.0 & 6.3 & 6.3 \\
\hline
\end{tabular}




\begin{tabular}{lllllllll}
\hline $101-1-14$ & N/A & N/A & N/A & 0 & 9.5 & 10.0 & 7.0 & 10.0 \\
$101-1-15$ & N/A & 7.8 & N/A & 7.8 & 6.4 & 7.5 & 4.0 & 7.5 \\
\hline
\end{tabular}

